\title{
O atendimento educacional especializado na visão dos diretores escolares
}

\author{
Ana Paula Marotto Homrich* \\ Universidade da Região de Joinville \\ Aliciene Fusca Machado Cordeiro** \\ Universidade da Região de Joinville
}

Resumo $\mathrm{O}$ presente artigo teve como objetivo conhecer como os diretores escolares compreendem o Atendimento Educacional Especializado nas escolas municipais em uma cidade de Santa Catarina. A metodologia pautou-se na abordagem qualitativa cujo instrumento utilizado para a coleta de dados foi um questionário. Para a interpretação dos dados utilizou-se a análise de conteúdo baseada em Bardin (2011) e Franco (2012). Dentre os autores que compuseram a fundamentação teórica destacam-se Libâneo, Paro, Meletti, Michels e Garcia. Verificou-se que o AEE é compreendido pela maioria dos diretores como um serviço centralizado no estudante público-alvo da Educação Especial ofertado na sala de recursos. Conclui-se que há necessidade da interferência dos diretores na viabilização de ações possibilitem a interface entre o professor especializado e os docentes das salas regulares.

PALAVRAS-CHAVE: Educação Especial; Atendimento educacional especializado; Diretor escolar. 


\section{The specialized educational servisse in the vision of the school principal}

Abstract This article aimed to know how school principals understand Specialized Educational Service - SES at municipal schools in a Catarinense city. The methodology based on the qualitative approach whose instrument used to collect data, was a questionnaire. The data comprehension required contents analysis based in Bardin (2011) and Franco (2012). Among the authors that composed theoretical fundamentals, highlighted Libâneo, Paro, Meletti, Michels, Garcia. It was found that SES is understood by the most principals as a centralized service on the student target audience of the Special Education offered in a resourced classroom. Concluding that there is a necessity of the principals interference on the viability of actions that enable an interface between the specialized teacher and the regular classrooms teachers.

KEYWORDS: Special Education; Specialized educational service; School principal.

\section{Introdução}

A Educação Especial no Brasil tem recebido maior atenção no campo das políticas públicas educacionais no decorrer das últimas décadas e, por causa disso, emerge a necessidade de as escolas se reorganizarem e se adequarem à heterogeneidade de seus estudantes.

Caiado, Campos e Viralonga (2011, p. 159) lembram que:

Desde a Constituição Brasileira de 1988 em que os direitos sociais foram afirmados, dentre eles, o direito à educação da pessoa com deficiência, que a legislação no país se amplia nessa área respondendo aos movimentos sociais que, nacional e internacionalmente, lutam pelos direitos das pessoas com deficiência.

Nesse contexto, ações políticas e pedagógicas referentes aos estudantes público-alvo da Educação Especial ganham ênfase nas discussões acerca da universalização da educação básica. Dentre elas, destaca-se a publicação da Política Nacional de Educação Especial na Perspectiva da Educação Inclusiva em 2008, que passou a orientar os sistemas educacionais para a organização dos serviços da Educação Especial, por meio do Atendimento Educacional Especializado, de forma a complementar o ensino regular, como oferta obrigatória e de responsabilidade dos sistemas de ensino.

Entretanto, a obtenção de direitos garantidos em lei não significa dizer que tudo ocorrerá com veemência, visto que as escolas se constituíram historicamente como espaços excludentes e a inclusão "[...] aparece como propulsora de uma nova visão da escola. Agora sob a narrativa do respeito às diferenças, oportuniza-se educação diferente para compensar as diferenças sociais" (MICHELS, 2006, p. 407). 
Nesse cenário, encontra-se o diretor escolar que "[...] pode articular-se tanto na conservação do status quo quanto com a transformação social, dependendo dos objetivos aos quais ele é posto a servir" (PARO, 2012, p.162).

A atuação do diretor frente à administração escolar, segundo Paro (2010, p. 25) permeia todo o processo administrativo e pedagógico, caracterizando-a como mediação dos recursos materiais e financeiros com o esforço humano, "[...] para a realização de fins determinados".

$\mathrm{Na}$ escola, os fins determinados estão relacionados aos objetivos estabelecidos no Projeto Político Pedagógico frente ao processo de escolarização dos estudantes (considerados ou não público-alvo da Educação Especial), os quais perpassam tanto pelo administrativo quanto pelo pedagógico. Assim sendo, a ação da gestão escolar não pode ser um processo separado da atividade educacional, visto que o diretor é, antes de tudo, um educador.

Em se tratando do Projeto Político Pedagógico, é oportuno lembrar que a participação coletiva na (re)elaboração do documento torna-se indispensável, pois, na medida em que as diretrizes são definidas em conjunto, a elaboração e efetivação das ações poderão ser feitas também em grupo. Nessa conjuntura, o Projeto Político Pedagógico é o principal norteador do processo de escolarização e por isso não se pode considerá-lo como mais um documento dos arquivos burocráticos educacionais e engavetá-lo, correndo o risco de perder uma de suas funções que é auxiliar na gestão democrática.

No que tange à gestão democrática, entende-se que o envolvimento de todos pode possibilitar a responsabilidade coletiva e a divisão de tarefas.

Contudo, emerge uma indagação pertinente à reflexões: Será que as escolas brasileiras estão organizadas para serem geridas democraticamente?

A despeito, Paro (2001, p. 52) afirma que:

[...] a democracia assim como não se dá espontaneamente, precisando, em vez disso, ser criada pela prática política, também precisa ter seus valores intencionalmente apropriados pela educação, visto que ninguém nasce democrata ou com os requisitos culturais necessários para o exercício da democracia. Daí a importância da escola ter, entre os objetivos da educação, a formação para a cidadania.

Compreende-se que para a constituição de uma escola democrática destinada a todos, inclusive aos estudantes público-alvo da Educação Especial, requer que algumas mudanças sejam pensadas e aplicadas nas escolas, como a revisão das metodologias, acessibilidade, temporalidade, condições de trabalho e formação docente, além de modificações nos currículos e nos instrumentos de avaliação. Em contrapartida, Freitas L., (2002, p. 300) alega que não vê possibilidades de tornar o sistema educacional em um sistema democrático, "[...] em meio a uma sociedade que aprofunda a injustiça do lado de fora da escola, mantém antigas e cria novas formas de exclusão dentro e fora da escola". 
A legislação promulgada para o Atendimento Educacional Especializado pode até apresentar uma proposta pedagógica com uma configuração diferente, no entanto, os impactos de exclusão sobre os estudantes não diferem. Todos os estudantes estão inseridos em uma mesma escola, mas a segregação permanece instaurada na medida em que existem espaços diferentes para o atendimento de estudantes público -alvo da Educação Especial.

Para compreender melhor a configuração do atendimento aos estudantes público-alvo da Educação Especial, surge este trabalho com o objetivo de conhecer como os diretores escolares compreendem o Atendimento Educacional Especializado.

\section{Os caminhos percorridos e os participantes da pesquisa}

Como ponto de partida, buscou-se pesquisas anteriormente realizadas e vinculadas ao projeto de pesquisa "Interfaces entre Atendimento Educacional Especializado, trabalho docente, formação de professores e políticas públicas”, cujo objetivo é conhecer as interfaces entre o Atendimento Educacional Especializado, trabalho docente, formação de professores e políticas públicas da região sul do Brasil. Bernardes (2014) teve como objetivo norteador de sua pesquisa conhecer o trabalho docente do Atendimento Educacional Especializado pelas vozes das professoras atuantes nesse serviço; Fuck (2014) investigou o Atendimento Educacional Especializado na concepção das professoras da Sala Comum; Santos (2016) buscou compreender como as professoras tornaram-se docentes no Atendimento Educacional Especializado; e Rabock (2016) pesquisou a concepção das professoras do Atendimento Educacional Especializado sobre infância, aprendizagem e desenvolvimento e a relação dessas concepções com o seu trabalho na Educação Infantil. Diante das discussões e resultados das pesquisas antepostas, fez-se necessário conhecer como os diretores escolares compreendem o Atendimento Educacional Especializado.

Realizou-se o balanço das produções acadêmicas para verificar o número de trabalhos disponíveis sobre a temática em discussão. Consultou-se as bases de dados da Coordenação de Aperfeiçoamento de Pessoal de Nível Superior - CAPES, Biblioteca Digital Brasileira de Teses e Dissertações - BDTD, as pesquisas da Associação Nacional de Pós-Graduação e Pesquisa em Educação - ANPEd no grupo de trabalho que aborda temáticas relacinadas à Educação Especial e a Biblioteca Científica Eletrônica do Scientific Eletronic Library Online - SciELO.

A busca limitou-se ao período compreendido entre os anos de 2010 e 2015, perfazendo um recorte de cinco anos.

No momento da busca, nenhum trabalho relacionado ao Atendimento Educacional Especializado e o diretor/gestor escolar estava disponível nos bancos de dados, evidenciando-se a necessidade de maiores investigações sobre a temática.

A base epistemológica desta pesquisa está fundamentada em alguns conceitos do materialismo histórico-dialético, adotando-se a visão de homem que "[...] percebe os sujeitos como históricos, datados, concretos, marcados por uma cultura como criadores de ideias e consciência que, ao produzirem e reproduzirem a realidade 
social são, ao mesmo tempo produzidos e reproduzidos por ela" (FREITAS, M., 2002, p.22). Este trabalho possui uma abordagem qualitativa e, devido ao número elevado de participantes, utilizou-se o survey como metodologia de pesquisa.

O local escolhido para a realização desta pesquisa foi um município de Santa Catarina, cujo número de matrículas na Rede Municipal de ensino no ano de 2015 foi de 46.623 estudantes no Ensino Fundamental Regular e, dentre eles, 737 (2\%) considerados público-alvo da Educação Especial (INEP, 2015).

Utilizou-se o questionário como instrumento para a coleta dos dados, o qual foi respondido por 41 participantes. A análise de conteúdo (BARDIN, 2011; FRANCO, 2012) foi o método usado nas análises. Primeiramente, organizou-se os dados em planilhas no programa Excel, em que os participantes foram identificados por meio de uma letra e um número que formaram uma nominação para cada sujeito de pesquisa (Diretor 1 = D1; Diretor $2=$ D2, e assim sucessivamente).

Posteriormente, os indicadores foram definidos por meio de um processo de classificação de elementos por recorrência. De acordo com Franco (2012, p. 60), "[...] em grande parte das investigações, qualquer que seja o tema explicitado, o mesmo passa a ter mais importância para a análise dos dados, quanto mais frequentemente for mencionado". As categorias foram definidas a priori tendo como base as perguntas do questionário.

Dentre o universo de 41 participantes, verificou-se que há representatividade maior de mulheres (29) do que de homens (12) na direção das escolas de Ensino Fundamental da Rede Municipal de Ensino do município; a maioria (25) encontra-se na faixa de idade entre 47 e 57 anos. Pode-se dizer que são docentes experientes, pois 25 profissionais possuem de 6 a 15 anos de trabalho docente em sala de aula. Com relação ao tempo de atuação na direção das escolas, 26 participantes estão entre seismeses a cinco anos na gestão escolar. Todos(as) possuem graduação visto que é um dos critérios exigidos para se candidatar ao cargo. Com relação à formação continuada, 39 diretores(as) tem especialização em cursos diversificados como Supervisão Escolar, Psicopedagogia, Interdisciplinaridade, Gestão Escolar, entre outros. Somente quatro diretores(as) fizeram Mestrado e nenhum(a) participante cursou Doutorado. A maioria possui experiência como docente em salas de aula com estudantes que apresentavam alguma deficiência.

Para ocupar o cargo de diretor(a) na cidade pesquisada, o(a) candidato(a) precisa cumprir alguns requisitos, tais como: ter um mínimo de cinco (5) anos de exercício profissional na Rede Municipal de Ensino, como professor efetivo, graduado em curso superior, em área do Magistério ou ter exercido a função de Supervisor Escolar ou Orientador Educacional por, no mínimo, dois (2) anos; não ter praticado ato que desabone a sua conduta profissional, comprovado mediante declaração do Núcleo de Recursos Humanos na Secretaria de Educação e Cultura - SEC, sob as penas da lei; ter exercido, preferencialmente, a função de diretor(a) ou auxiliar de direção por no mínimo dois (2) anos. 


\section{O Atendimento Educacional Especializado na compreensão dos diretores escolares}

Para análise da compreensão apresentada pelos(as) diretores sobre o Atendimento Educacional Especializado, tomou-se como referência as seguintes perguntas do questionário: $\mathrm{O}$ que você entende por Atendimento Educacional Especializado? Quem são os estudantes público-alvo do Atendimento Educacional Especializado? Para você, como deve ser desenvolvido o trabalho pelo professor do Atendimento Educacional Especializado?

Constatou-se que o Atendimento Educacional Especializado é compreendido pelos(as) diretores(as) como o serviço oferecido em uma sala de recursos multifuncionais ( 7 recorrências), tendo um profissional capacitado (professor especializado) como responsável pelo atendimento (5 recorrências). É também visto como suporte aos professores ( 7 recorrências) e suporte às famílias (1 recorrência). Todavia, a maioria dos(as) diretores(as) (35 recorrências) compreende o Atendimento Educacional Especializado como o atendimento centralizado nos estudantes público-alvo da Educação Especial.

Ressalta-se que em pesquisas realizadas também nesta mesma Rede Municipal de Ensino, Bernardes (2014) e Fuck (2014) verificaram a centralidade do serviço do Atendimento Educacional Especializado no estudante por meio da maioria das respostas dos professores das salas de recursos multifuncionais e das salas de ensino regular, convergindo ao entendimento apresentado pelos(as) participantes desta pesquisa.

Esta centralidade pode levar a uma estigmatização individualizada do estudante, já que ele não faz parte de um padrão homogêneo esperado pela escola, podendo ocorrer "[...] a coisificação e desumanização do estigmatizado, já que o indivíduo é transformado em sua própria diferença, [...] e sua deficiência passa a ser seu único atributo, com uma carga social de desvantagem e descrédito" (MELETTI, 2006, p. 7).

Ao relacionarem o Atendimento Educacional Especializado à sala de recursos multifuncionais, os(as) diretores(as) seguem o que está promulgado nos documentos legais. Conforme as Diretrizes Operacionais da Educação Especial para o Atendimento Educacional Especializado na Educação Básica, o trabalho deve ser "[...] realizado, prioritariamente, na sala de recursos multifuncionais da própria escola ou em outra escola de ensino regular, no turno inverso da escolarização [...]" (BRASIL, 2009, p.2).

Ressalta-se que o Atendimento Educacional Especializado desenvolvido nas salas multifuncionais, com função suplementar e complementar ao trabalho a ser desenvolvido pelos professores do ensino regular, não contribui para o desenvolvimento de um trabalho pedagógico articulado, visto que mantém "[...] a opção pelo modelo hegemônico de educação especial, mais especializado que pedagógico mais centrado nos recursos que nos conhecimentos" (GARCIA, 2009, p. 4). 
Neste sentido, as ações pedagógicas precisam estar articuladas entre os docentes da sala comum e da sala de recursos multifuncional. Diante deste cenário, a atuação do(a) diretor(a) torna-se indispensável para a viabilização de encontros entre os professores do ensino regular e professores especializados, para que possam refletir sobre as especificidades dos estudantes e, coletivamente, planejar ações voltadas à eliminação de barreiras que eventualmente possam surgir durante o processo de escolarização. Contudo, a forma como o sistema de ensino está organizado no Brasil pouco propicia a disponibilidade de tempo para estudos, discussões e planejamentos coletivos.

Com relação à compreensão apresentada pelos(as) participantes sobre o Atendimento Educacional Especializado, estar vinculado ao trabalho realizado pelo professor especializado pode inferir que, na visão dos(as) diretores(as), a responsabilidade pelo atendimento dos estudantes público-alvo da Educação Especial passa a ser somente de um profissional sem que haja uma articulação com os demais docentes da escola. "O trabalho assim entendido e praticado admite que este não necessariamente precise acontecer no contexto escolar, já que não há as conexões com a sala de aula comum"(BERNARDES, 2014, p. 103).

No tocante à compreensão sobre o Atendimento Educacional Especializado como suporte aos professores, percebe-se que os(as) diretores(as) dão ênfase à elaboração e uso de materiais pedagógicos e criação de estratégias por parte do professor especializado. Em se tratando dos materiais pedagógicos, acredita-se que eles precisam estar à disposição de todos os docentes para serem usados em diferentes ocasiões e ambientes da escola e, desta forma, ajudar na eliminação de barreiras que venham impossibilitar o aprendizado dos estudantes.

Ao analisar o conjunto de respostas dos(as) diretores(as), é possível sintetizar suas compreensões sobre o Atendimento Educacional Especializado como um trabalho fragmentado, centrado no estudante público-alvo da Educação Especial, realizado por uma professora especializada em uma sala de recursos multifuncionais.

Ressalta-se que esse entendimento está respaldado na Política Nacional de Educação Especial na Perspectiva da Educação Inclusiva (BRASIL, 2008). Ante ao exposto, Michels (2006, p. 408, grifo da autora) acresce que:

[...] por mais que as legislações e as normas instituídas conformem práticas, estas serão apreendidas por sujeitos que darão vida a estes encaminhamentos políticos. Os sujeitos envolvidos entendem as indicações políticas de maneira distinta, conforme suas vivências, seus interesses, sua organização profissional, entre outros. Cada instituição educacional acaba por "implementar" as políticas à sua maneira $[\ldots]$

A autora supracitada indica que é no embate entre a proposição política e o cotidiano que a escola vai se constituindo e se organizando. "É justamente nessa relação que se faz importante refletir sobre a política educacional em curso e o papel atribuído à educação e à escola no Brasil” (MICHELS, 2006 p. 408). 
Diante desse contexto, entende-se que intervenções dos(as) diretores(as) podem favorecer a realização de um trabalho que envolva todos os professores, funcionários, equipe diretiva e famílias, do contrário o Atendimento Educacional Especializado tenderá a ser compreendido e praticado como nos moldes anteriores ao que era oferecido fora da escola para estudantes público-alvo da Educação Especial, realizado de forma segregada em espaços diferenciados. Para Michels, Carneiro e Garcia (2010, p. 6) "[...] a manutenção de velhos modelos mediante novas políticas pode significar uma minimização das aprendizagens propostas para grande parte dos alunos, na direção de um empobrecimento dos conteúdos a serem trabalhados na educação básica", pois, com essa compreensão compartimentalizada dos(as) diretores(as) a possibilidade de o estudante público-alvo da Educação Especial ter acesso aos conteúdos pedagógicos e escolarizados pode se tornar mais complexa e difícil. Acredita-se que para atingir o objetivo de eliminar barreiras, não basta trabalhar com o estudante e suas necessidades educativas diferenciadas de maneira segregada.

Todavia é oportuno lembrar que a educação brasileira reflete a sociedade na qual está inserida e consequentemente pode corroborar com a segregação. A escola sofre a determinação do conflito de interesses por ser "[...] inteiramente dependente da estrutura social geradora de marginalidade" (SAVIANI, 1997, p. 16). Contudo o autor anteposto defende que a função primordial da escola é possibilitar a todos os estudantes o acesso aos conhecimentos historicamente produzidos e sistematizados, com o objetivo dos sujeitos conhecerem o mundo de modo que possam analisar e intervir na realidade. Para Saviani (1997, p. 74), isso "[...] implica a igualdade de acesso ao saber, portanto a distribuição igualitária dos conhecimentos disponíveis".

No que tange ao grupo de estudantes a quem o Atendimento Educacional Especializado é destinado, de acordo com a Política Nacional de Educação Especial na Perspectiva da Educação Inclusiva (2008), o público-alvo da Educação Especial é composto por estudantes com deficiência, transtornos globais do desenvolvimento e altas habilidades/superdotação.

Observou-se que os(as) diretores(as) demonstraram ter conhecimento do que está promulgado na legislação, contudo a ênfase é dada aos estudantes com deficiência, transtornos ou síndromes (34 recorrências).

Essa compreensão pode levar os(as) diretores(as) a correrem o risco de orientar um trabalho pedagógico voltado para o que falta no estudante enfatizando os aspectos clínicos em detrimento ao ensino de conteúdos escolarizados. Sobre isso, Garcia (2008, p. 17) alega que

[...] o trabalho pedagógico voltado a sujeitos com deficiência [...] vem permeado de ações e estratégias com pouca organicidade em relação à Educação Básica, organizado no modelo de sobreposição de programas e serviços voltados à diversidade do alunado a uma estrutura excludente. 


\section{O entendimento do(a) diretor(a) sobre o trabalho desenvol- vido pelo professor do Atendimento Educacional Especiali- zado}

Quando questionados sobre como deve ser desenvolvido o trabalho pelo professor do Atendimento Educacional Especializado, os(as) participantes descreveram meios diversos, os quais foram organizados em indicadores de acordo com o número de recorrências.

Para os(as) diretores(as), o trabalho do professor especializado é visto como suporte aos professores (17 recorrências); atendimento individualizado aos estudantes (17 recorrências); um trabalho com ênfase aos aspectos pessoais do professor (13 recorrências); criação de estratégias e recursos pedagógicos (11 recorrências); envolvimento e apoio às famílias (7 recorrências); atendimentos aos estudantes em grupos (3 recorrências).

Alguns diretores utilizam a expressão "parceria" para designar o trabalho como suporte aos demais docentes. No entanto a pesquisa de Bernardes (2014) constatou que o trabalho de parceria entre as professoras da sala comum e da sala de recursos multifuncionais, apesar de essencial, acontece esporadicamente e na maioria das vezes quando a professora especializada percebe a necessidade ou quando a professora da sala comum solicita.

Diante desse contexto acredita-se na ação do diretor escolar para possibilitar as interlocuções entre os professores da sala de aula comum e os professores especializados, visto que, conforme Libâneo (2015), as escolas vêm sendo pressionadas a repensar seu papel diante das transformações sociais e "[...] quando se trata de preparação cultural e científica das novas gerações para enfrentamento das exigências postas pela sociedade contemporânea" (LIBÂNEO, 2015, p. 56), as escolas são insubstituíveis.

Ressalta-se que atrelados às transformações impostas à escola, encontramse o medo, a dúvida e a incerteza de como agir quando se está diante de uma situação nova que exige a criação de estratégias para viabilizar práticas que conduzam a caminhos sobre os quais justamente pouco se sabe. Sobre isso, Cardozo (2016, p. 66) faz algumas reflexões:

[...] estarão algum dia os professores preparados para lidar com a diferença, com o novo, com o imprevisível? Se a noção que permeia o discurso da falta de preparo for o de que estar preparado significa estar pronto, estar acabado, então se compreende que este preparo, tão esperado, não acontecerá. O que pode acontecer é um preparar permanentemente, utilizar a dúvida, a insegurança, o despreparo e a impotência como terreno para a problematização, a crítica, a reflexão e a construção coletiva de caminhos para se trabalhar com o que emerge de novo no contexto escolar.

Com relação ao preparo permanente citado pela autora sobreposta, está a formação docente continuada, a qual pode ser considerada uma das funções da gestão escolar. 
Entende-se que as formações necessitam de um arcabouço teórico que embase as discussões referentes às ações pedagógicas realizadas pelos professores e demais profissionais que atuam no processo educacional.

Conforme pesquisa realizada por Borowsky (2010, p. 17), no que se refere às formações continuadas, constata-se que

[...] elas vêm hoje expandidas como formação continuada feita em serviço, o que garante economia de tempo e dinheiro ao Estado, e na modalidade à distância, sob o discurso da democratização do ensino, oferecendo uma formação rápida e com custos menores a milhares de professores no país.

Conforme a autora anteposta, a centralidade da formação continuada está nos métodos e técnicas de como ensinar, em uma perspectiva prática, instrumental e tecnicista, além de ser ofertada predominantemente pela modalidade à distância. "O fato de disseminar tal formação ao maior número de pessoas possível parece ter implicações importantes como uma formação aligeirada e precarizada" (BOROWSKY, 2010, p. 44).

Não obstante, os(as) diretores(as) também entendem que o trabalho do professor especializado deve ser desenvolvido por meio do atendimento individualizado aos estudantes. Entende-se que o processo educacional também perpassa pelo trabalho individualizado com os estudantes, todavia não pode limitar-se aos atendimentos na sala de recursos multifuncional. $O$ trabalho individualizado também precisa ocorrer nas salas regulares e em todos os espaços escolares frequentados pelos estudantes. ele precisa

Sobre o trabalho do professor especialista, Fuck (2014, p. 131) acresce que

[...] contemplar as especificidades observadas no coletivo, naquilo que o aluno não conseguiu realizar no grupo [...] que necessitam de maior investigação, de proposições diferenciadas [...] que só adquirem significado quando do individual retornam para o coletivo, ampliando as oportunidades de aprendizagem e participação do aluno.

Alguns(as) diretores(as) também entendem que o trabalho realizado pelo professor do Atendimento Educacional Especializado está relacionado aos aspectos pessoais desse profissional. "O professor precisa ser bem dedicado e esforçado" (D1); "[...] que tenha paciência, respeito" (D8); "Com dedicação, estudo, amor acima de tudo" (D15); “Com muito carinho, paciência, inovação e dedicação” (D17).

Ao pensar no trabalho do professor especializado baseado em aspectos relacionais, $o(a)$ diretor(a) pressupõe que deva existir um perfil específico para trabalhar com estudantes público-alvo da Educação Especial. Para Santos (2016, p. 92-93), ao assumir essa postura, valoriza-se "[...] a dimensão afetiva e relacional da prática pedagógica, mas pouco menciona outras dimensões igualmente importantes, como saberes e técnicas pedagógicas". É necessário que ele tenha domínio dos métodos pedagógicos, técnicas e saberes condizentes a sua prática. Trata-se de um processo que visa o desenvolvimento de competências profissionais que segundo Roldão (2005, p. 14) "[...] dão 
corpo a um saber profissional, um elemento central no exercício da profissão, que se consubstancia essencialmente na ação de ensinar".

Por essas razões, ao compreender o professor especializado por meio de adjetivos afetivos, os(as) diretores(as) tiram "[...] o foco do que confere à docência o status de profissão e lhe diferencia das demais atividades profissionais" (SANTOS, 2016, p. 77).

Nessa conjuntura, o(a) diretor(a) tem um papel fundamental, visto que sua concepção sobre o trabalho dos professores pode abrir espaço para o aprendizado dos estudantes ou justificar o não aprender dos mesmos.

Dando continuidade às análises, constatou-se que apenas 3 diretores(as) entendem o trabalho realizado pelo professor especializado por meio de atendimentos em grupos. Diante disso, presume-se que ainda seja preciso refletir sobre a importância das relações interpessoais nos processos educacionais visto que a ênfase maior está sendo dada aos atendimentos individualizados.

Como culminância das análises, destaca-se que os(as) diretores atribuem vasta lista de atividades ao professor especializado. "Com um olhar mais atento, é possível perceber que suas funções vão muito além do atendimento na sala de recursos. Trata-se de um trabalho colaborativo que ultrapassa até mesmo os muros da escola" (FUCK; CORDEIRO; RENGEL, 2016, p. 482).

Findadas as análises, infere-se que o(a) diretor(a) “[...] defronta-se por um lado, com as normatizações hierárquicas historicamente construídas que delimitam as condições do seu trabalho e, por outro, com a diferença e o diferente, que passam a habitar a escola" (FUCK; CORDEIRO; RENGEL, 2016, p. 483).

Frente às constatações, destaca-se que os discursos legais podem respaldar esse entendimento apresentado pelos(as) diretores(as) sobre o Atendimento Educacional Especializado compartimentado sem que eles tenham consciência de tal fato.

Ainda sobre os discursos legais, $\operatorname{Vaz}(2013$, p. 44) corrobora que eles têm um "[...] caráter impositivo e direcionador que muitas vezes utiliza argumentos com caráter humanista para convencer a população sobre seus objetivos". A autora ainda acresce que "[...] a abrangência dos discursos de convencimento e adesão é muito significativa e faz parte de uma concepção de sociedade cuja intenção primordial é manter as relações antagônicas entre o capital e o trabalho" (VAZ, 2013, p.44-45). Ante ao exposto, infere-se que os(as) diretores(as) podem estar se apropriando da legislação a partir de suas concepções e esta apropriação pode ocorrer tanto por meio de movimentos hegemônicos como por movimentos contra hegemônicos.

\section{Considerações finais}

Por meio das análises, verificou-se que o Atendimento Educacional Especializado é compreendido pela maioria dos(as) diretores escolares como um serviço centrado no estudante público-alvo da Educação Especial. Esse entendimento reforça 
a concepção de uma escola marcada por critérios seletivos ancorados na visão homogeneizadora de ensino, dentro da qual alguns estudantes são rotulados e muitas vezes permanecem à margem da escolarização no ensino regular, mesmo estando inseridos em um mesmo espaço escolar.

A compreensão do Atendimento Educacional Especializado limitada a uma sala de recursos multifuncionais ratifica a ideia de setorização, já que as atividades devem ser realizadas preferencialmente nesses "[...] ambientes dotados de equipamentos, mobiliários e materiais didáticos e pedagógicos para a oferta do atendimento" (BRASIL, 2011). Esse entendimento avigora o modelo hegemônico de educação especial, mais especializado que pedagógico na medida em que as ações estão mais centradas nos recursos presentes na sala de recursos multifuncionais do que na apreensão de conhecimentos (GARCIA, 2009).

Destaca-se que a visão apresentada pelos(as) diretores(as) sobre o Atendimento Educacional Especializado associada ao trabalho do docente especializado, sem haver articulação com a sala regular, de acordo com as afirmações de Michels, Carneiro e Garcia (2010), pode acarretar na minimização da apreensão de conhecimentos escolarizados por parte dos estudantes, na direção de um empobrecimento dos conteúdos em detrimento da supervalorização do uso de técnicas e recursos. Pensar assim pode caracterizar-se como uma forma de silenciamento da ação pedagógica.

Acredita-se que o(a) diretor(a) precisa oportunizar a interface entre o Atendimento Educacional Especializado e o trabalho desenvolvido na sala comum, proporcionando momentos para a realização de planejamentos coletivos entre os docentes do ensino regular e o professor especializado, com vistas a alcançar o principal objetivo da escola que é a aprendizagem e o desenvolvimento dos estudantes.

\section{Referências}

BARDIN, Laurence. Análise de conteúdo. São Paulo. SP. Edições 70, 2011.

BERNARDES, Cleide Aparecida Hoffmann. Trabalho docente nas salas de recursos multifuncionais: concepções de professores do AEE. Orientadora: Dra Aliciene Fusca Machado Cordeiro - Dissertação de Mestrado em Educação. Joinville-SC: UNIVILLE, 2014.

BOROWSKY, Fabíola. Fundamentos teóricos do curso de aperfeiçoamento de professores para o Atendimento Educacional Especializado (2007): novos referenciais? Orientadora: Maria Helena Michels -. Dissertação de Mestrado em Educação - Universidade Federal de Santa Catarina, Florianópolis, 2010.

BRASIL, Política Nacional de Educação Especial na perspectiva inclusiva. Brasília, DF: MEC/SEESP, 2008.

BRASIL. Ministério da Educação. Conselho Nacional de Educação. Câmara de Educação Básica. Institui Diretrizes Operacionais para o Atendimento Educacional Especializado na Educação Básica, modalidade Educação Especial. Diário Oficial da Educação, Brasília, DF 2009. Seção 1, p. 17. Disponível em: http://portal.mec.gov.br/dm documents/rceb004_09pdf. Acesso em: 04/07/2016.

BRASIL. Decreto no 7.611, de 17 de novembro de 2011. Dispõe sobre a educação especial, o atendimento educacional especializado e dá outras providências. Diário Oficial da União, Brasília, DF, 18 nov. 2011. Disponível em: <www.planalto.gov.br> Acesso em: 12/06/2015 
CAIADO, Katia Regina Moreno, CAMPOS, Juliane Aparecida de Paula Perez, VILARONGA, Carla Ariela Rios. Estudo exploratório sobre o perfil, a formação e as condições de trabalho do professor. In: CAIADO, Katia Regina Moreno, JESUS, Denise Meyrelles, BAPTISTA, Claudio Roberto (Orgs). Porto Alegre: Mediação/CDV/FACITEC, Volume 1, 2011.

CARDOZO, Fabiana Ramos da Cruz. Formação continuada de professores dos cursos de Pedagogia do Sistema ACAFE para o trabalho com acadêmicos com deficiência. Orientadora: Dra. Sonia Maria Ribeiro. - Dissertação de Mestrado em Educação. Joinville-SC: UNIVILLE, 2016.

FRANCO, Maria Laura P. B. Análise de conteúdo. 4. ed. Brasília: Liber Livro, 2012.

FREITAS, Maria Teresa de Assunção. A abordagem sócio-histórica como orientadora da pesquisa qualitativa. Cad. Pesquisa (online). 2002, n.116, pp. 21-39 ISSN 0100-1574.

FREITAS, Luiz Carlos. A Internalização da Exclusão. Educ. Soc., Campinas, vol. 23, n. 80, setembro/2002, p. 299-325. Disponível em: <http://www.cedes.unicamp.br>. Acesso em: 06/10/2016.

FUCK, Andréia Heiderscheidt. O Atendimento Educacional Especializado nas salas de recursos multifuncionais na concepção dos professores da sala comum. Orientadora: Dra Aliciene Fusca Machado Cordeiro - Dissertação de Mestrado em Educação. Joinville-SC: UNIVILLE, 2014.

FUCK, Andréia Heiderscheidt; CORDEIRO, Aliciene Fusca Machado; RENGEL, Juliana Testoni dos. As concepções das professoras da sala comum sobre o Atendimento Educacional Especializado e os processos de escolarização dos alunos com deficiência. Revista Contrapontos - Eletrônica Vol. 16 - n. 3 - Itajaí, set-dez 2016 p. 471-490. Disponível em Disponível em: www.univali.br/periodicos. Acesso em 10 de março de 2017.

GARCIA, Rosalba Maria Cardoso. Política de educação inclusiva e trabalho pedagógico: uma análise do modelo de educação especial na educação básica. Anais. IV Seminário Nacional de Pesquisa em Educação Especial: Conhecimento \& Margens. Gramado: RS, 2008.

GARCIA, Rosalba Maria Cardoso. Política nacional de educação especial nos anos 2000: a formação de professores e a hegemonia do modelo especializado. In: V Seminário Nacional de Pesquisa em Educação Especial: formação de professores em foco - 2009. São Paulo. Anais eletrônicos. São Paulo: V Seminário Nacional de Pesquisa em Educação Especial: formação de professores em foco, 2009.

INEP- Instituto Nacional de Estudos e Pesquisas Educacionais Anísio Teixeira (www.portal.inep.gov.br/basica-censo). Acesso em março de 2015.

LIBÂNEO, José Carlos. Organização e Gestão da Escola: Teoria e Prática. $6^{a}$ edição revisada. e ampliada- São Paulo : Heccus Editora, 2015

MELETTI, Silvia Márcia Ferreira. Educação escolar da pessoa com deficiência mental em instituições de educação especial: da política à instituição concreta. Orientadora Maria Helena de Souza Patto. São Paulo, 2006. 125 p. Tese (Doutorado - Programa de Pós-Graduação em Psicologia. Área de Concentração: Psicologia Escolar e do Desenvolvimento Humano) - Instituto de Psicologia da Universidade de São Paulo.

MICHELS, Maria Helena. Gestão, formação docente e inclusão: eixos da reforma educacional brasileira que atribuem contornos à organização escolar. Revista Brasileira de Educação, v.11 no 33 set/dez 2006.

MICHELS, Maria Helena. CARNEIRO, Maria Sylvia Cardoso, GARCIA, Rosalba Maria Cardoso. A articulação entre serviço especializado e classe comum: A organização curricular frente a um modelo inclusivo. 2010. Disponível em: www.portalanpedsul.com.br Acesso em: 06 mar. 2016. 
PARO, Vitor Henrique. A Gestão da Educação ante as exigências de qualidade e produtividade da escola pública. In: SILVA, L. H. (org.). A Escola Cidadã no contexto da Globalização. Petrópolis: Vozes, 2001.

Gestão escolar, democracia e qualidade do ensino. São Paulo: Ática, 2007.

A educação, a política e a administração: reflexos sobre a prática do diretor escolar. Educação e Pesquisa, São Paulo, v.36, p.763-778, set/dez. 2010.

.Administração Escolar: Introdução crítica. 16 ed. São Paulo: Cortez, 2012.

RABOCK, Daiana. Concepções das professoras do Atendimento Educacional Especializado com foco em crianças dos centros de Educação Infantil. Orientadora Dra Aliciene Fusca Machado Cordeiro - Dissertação de Mestrado em Educação. Joinville-SC: UNIVILLE, 2016.

ROLDÃO, M.C. Formação de professores, construção do saber profissional e cultura da profissionalização: que triangulação? In: ALONSO, L. ROLDÃO, M.C. (Coord.). Ser professor do $1^{\circ}$ ciclo, construindo a profissão. Coimbra: Edições Almedina, 2005. p. 13-25.

SANTOS, Juliana Testoni. Professoras atuantes no Atendimento Educacional Especializado e suas histórias de vida: Um estudo sobre identidade docente. Orientadora Dra Aliciene Fusca Machado Cordeiro - Dissertação de Mestrado em Educação. Joinville-SC: UNIVILLE, 2016.

SAVIAVI, Dermeval, Escola e democracia: teorias da educação, curvatura da vara, onze teses sobre educação e política - 31 ed.- Campinas, SP: Autores Associados, 1997. Coleção Polêmicas do nosso tempo; v. 5.

VAZ. Kamille. $\mathrm{O}$ professor de educação especial nas políticas de perspectiva inclusiva no Brasil: concepções em disputa. Dissertação de Mestrado. Universidade Federal de Santa Catarina. Florianópolis. 2013.

* Mestranda em Educação na Universidade da Região de Joinville, Joinville, Santa Catarina, Brasil.

** Professora doutora da Universidade da Região de Joinville, Joinville, Santa Catarina, Brasil.

\section{Correspondência}

Ana Paula Marotto Homrich - Universidade da Região de Joinville, Colégio da UNIVILLE. Rua Paulo Malschitzki , no 10, Zona Industrial Norte. CEP: 89219710. Joinville, Santa Catarina, Brasil.

E-mail: aphomrich@yahoo.com - aliciene_machado@hotmail.com

Recebido em 17 de abril de 2017

Aprovado em 25 de setembro de 2017 